ISSN 1397-4831

WORKING PAPER 03-25

Tom Coupé, Valérie Smeets and Frédéric Warzynski

Incentives in Economic Departments: Testing Tournaments?

Department of Economics

Aarhus School of Business 


\title{
Incentives in Economic Departments: Testing Tournaments?*
}

\author{
Tom Coupé† Valérie Smeets ${ }^{\ddagger} a n d$ Frédéric Warzynski ${ }^{\S}$
}

\begin{abstract}
Existing tests of tournament theory have recently been criticized for their failure to distinguish tournaments from other theories that have similar effects like standards and marginal productivity theory (Gibbs, 1994, 1996; Prendergast, 1999). In this paper, we propose a series of empirical tests that allow to make this distinction. We use a dataset of average wages by rank in US economic departments over the period 1977-1997 and link this information to individual production data to test whether wage gaps affect the productivity and cooperative behavior of economists and to control for marginal productivity theory. We find that the wage gap is increasing along the hierarchy, even when controlling for production by rank. Moreover, wages are more sensitive to productivity for higher ranks. We find some evidence that higher wage gaps lead to higher productivity but not that wage gaps depend on the number of contestants nor that they lead to less cooperation.
\end{abstract}

${ }^{*}$ We thank Charles Scott and John Siegfried for allowing us to use the UAQ salary data. The paper benefitted from comments by Mathias Dewatripont, Tor Eriksson, Ed Lazear, Patrick Legros, Canice Prendergast and by seminar participants at University College London student seminar, Trinity College Dublin, 2002 Jamboree in Toulouse, University of Liège, the Day for Belgian Labor Economists, the North American Summer Meeting of the Econometric Society, Universidad Carlos III Madrid and Aarhus School of Business. All errors are ours.

${ }^{\dagger}$ EERC, Kiev, e-mail: tcoupe@eerc.kiev.ua

${ }^{\ddagger}$ Aarhus School of Business and ECARES, Université Libre de Bruxelles, e-mail: vas@asb.dk

${ }^{\S}$ Aarhus School of Business, e-mail: fwa@asb.dk 
These findings tend to go in favor of the use of standards rather than tournaments in economic departments.

JEL Codes: J0, M5

Keywords: incentives, sorting, tournaments, standards, marginal productivity, economic departments

"No matter what we may say, none of us is a philosophersaint, and you can't fully understand the development of economic ideas without a sense of the structure of rewards that economists face",

Paul Krugman, Incidents from my career, www.wws.princeton.edu/ ${ }^{\text {pkrugman/incidents.html }}$

\section{Introduction}

A large literature has examined how relative performance evaluation (RPE) schemes are helpful to improve the incentives provided by an organization to its employees and to induce sorting of the most able individuals. In this paper, we analyze the wage policy of U.S. economic departments over the period 1977-1997 and link it to tournament theory (Lazear and Rosen, 1981), the first and more popular of these RPE theories. Tournament theory has several implications about the way wages are structured in the hierarchy so as to generate incentives and about the way individuals react to these incentives.

The empirical literature testing tournament theory has mostly focused on executive pay (see e.g. Eriksson, 1999; Conyon et al., 1999 and Bognanno, 2001 for recent exercises), where only the absolute top of the hierarchy was considered and individual productivity was proxied by firm performance; or more naturally on sport tournaments (see e.g. Ehrenberg and Bognanno, 1990a\&b and Becker and Huselid, 1992) where individual performance is immediately retrievable, but hierarchies are absent.

We extend the analysis to the academic world and more specifically to the case of economic departments. The academic profession combines two 
important aspects: first, there is a well-established three-layers hierarchy, and second, it is possible to obtain measures of individual productivity and cooperation since entry on the labor market, and therefore at each hierarchical level, by looking at publications patterns. In a more and more competitive academic environment, wage policy should be a key tool not only for providing incentives but also for keeping and reallocating scarce talent.

Another important criticism against existing papers is that most studies did not test tournaments against other theories like standards or basic theories of marginal productivity that have similar predictions (Gibbs, 1994, 1996; Prendergast, 1999). This is the main contribution of our paper, as we run a series of empirical tests that allow us to distinguish between these three theories.

We try to answer two questions. What are the main determinants of the wage policy in an economic department, and more importantly, does the wage structure influence the behavior of economists and how? To answer these questions, we link our average wage by rank dataset to individual productivity and cooperation data to assess the consequences of wage gaps. We use the composition of economic departments in the 107 universities which were ranked by the NRC in 1993 and link names to the bibliographic information provided by EconLit. We also use the fact that we have information on the entire population of the department to compute the average productivity by rank, so as to link the wage gap to the differences of productivity of the different ranks to control for marginal productivity theory.

We find that the wage gaps are increasing with rank. This finding is robust when controlling for productivity differences, and productivity differences also explain part of the wage gap. Wages become more linked to performance at higher ranks, indicating a sorting effect as more productive individuals are allocated to higher pay jobs along the career. We also find evidence that wage gaps lead to more productivity. However, the wage gap does not appear to be affected by the number of contestants, nor does it influence cooperation among contestants. The evidence therefore suggests the use of standards rather than tournaments in economic departments, and 
also the existence of a learning process about the talent of individuals along the career, resulting in the sorting of individuals.

\section{Theory and Empirical Predictions}

This section introduces our main hypotheses and compares implications from tournament theory, standards and marginal productivity theory. It also discusses the intuition of our empirical strategy to distinguish between these three theories.

\subsection{Tournaments}

Tournaments are a simple form of RPE where people receive a wage premium if they beat their competitor. An analogy can easily be drawn with sport contests, such as a sprinter winning a race, and can also be applied for promotions along the hierarchy, for example in the succession of a CEO or more generally for the allocation of individuals to higher responsability levels. We provide hereafter a simplified version of Lazear and Rosen (1981).

The output produced by individual $i$ is stochastic and depends on effort $a:$

$$
q_{i}=a_{i}+\varepsilon_{i}
$$

There is a cost of effort $\Psi\left(a_{i}\right)$. There exists another worker $j$ with similar characteristics. The measurement error can itself be divided in two terms: a term common to both workers reflecting the risk linked to the environment $(\nu)$ and an individual specific noise $\xi_{k}, k=i, j$.

Suppose the wage of the worker is a combination of a fixed part $t$ and a prize for winning $W$, so that the expected payment is $t+p W$, where $p$ is the probability of winning the tournament:

$$
p=\operatorname{Pr}\left(q_{i}>q_{j}\right)=\operatorname{Pr}\left(a_{i}-a_{j}>\xi_{j}-\xi_{i}\right)=G\left(a_{i}-a_{j}\right)
$$

where $G$ is the cumulative distribution function of normal $\xi_{j}-\xi_{i}$ with mean 0 and variance $2 \sigma_{\xi}^{2}$. 
The agent therefore selects effort that maximizes his utility function $t+p W-\Psi(a):$

$$
W g\left(a_{i}-a_{j}\right)=\Psi^{\prime}\left(a_{i}\right)
$$

where $g$ is the probability distribution function. By symmetry $a_{i}=a_{j}$. Assuming for simplicity that $\Psi(a)=\frac{a^{2}}{2}$, by selecting $W=\frac{1}{g(0)}$ the principal can achieve the first best. More generally, the higher the gap, the higher the effort exerted by the contestants.

This literature has since been extended and detailing the various developments is beyond the scope of this paper. We focus our attention to testable hypotheses.

\section{Hypothesis 1: the value of winning should increase as one goes up the promotion ladder (Rosen, 1986).}

The intuition is that in a sequential game with $N$ stages and $s$ stages remaining to be played, prizes are increasing in survival: $\Delta W_{s}>0 \forall s$. Winning one step further gives the option to continue, but since there are fewer steps remaining, the option value that determines the incentives of the players plays out, so the wage gap must reflect the loss of the survival option.

\section{Hypothesis 2: the wage spread should be higher the more there are contestants for the prize (McLaughlin, 1988)}

This is a very intuitive finding: the more people are fighting for a prize, the more difficult it is to obtain it, and the higher the prize should be to provide the same level of incentives. While equilibrium effort is not affected, the wage spread is increasing in the number of contestants ${ }^{1}$.

\footnotetext{
${ }^{1}$ As noted by Eriksson (1999), it is less obvious to find how the level of effort affects the probability of winning as the number of contestants increases. See also Nalebuff and Stiglitz (1983).
} 


\section{Hypothesis 3: higher wage gaps should be associated with higher productivity}

This proceeds directly from the theory, as higher gaps lead to better incentives. This implies that universities with higher gaps should perform better, either in terms of publications or in terms of rankings.

\section{Hypothesis 4: higher wage gaps should reduce coopera- tive behavior among contestants (Lazear, 1989)}

While competition among contestants provides incentives to exert more effort, it could also discourage contestants to cooperate, or even induce them to sabotage each other's work. It might therefore be efficient to have lower wage gaps to avoid this negative sabotage behavior, at the expense of lower productive effort.

\section{$2.2 \quad$ Standards}

Standards are another simple form of promotion scheme, where all individuals who reach an established threshold are promoted. The stylized model and discussion below is based on Gibbs (1996). Instead of beating their competitor (a moving target), workers must now beat the standard $S$ established ex ante by the firm. This means that the probability of being promoted becomes:

$$
p=\operatorname{Pr}\left(q_{i}>S\right)=1-\operatorname{Pr}\left(S-a_{i}>\varepsilon_{i}\right)=1-H\left(S-a_{i}\right)
$$

where $H$ is the cumulative distribution function of a normal with mean 0 and variance $\sigma_{\varepsilon}^{2}$. The first order condition becomes:

$$
W h\left(S-a_{i}\right)=\Psi^{\prime}\left(a_{i}\right)
$$

where $h$ is the probability distribution function. Incentives are larger when $a^{*}=S$. By setting $W=\frac{1}{h(0)}$, the principal can obtain first best effort. Therefore the wage gap (hypothesis 3 ) has the same incentive property 
than in the tournament model. It is also still the case that hypothesis 1 holds following the same reasoning. However, hypotheses 2 and 4 no longer hold, because the other contestants of the game are not true competitors. Standards are therefore a safeguard against the potential negative sabotaging effects of tournaments.

There are other differences between standards and tournaments that are worth stressing. First, standards do not filter out the common term. When there is a lot of common uncertainty, tournaments provide a form of insurance from the external environment. Second, by imposing a minimum level of absolute performance, standards provide a better selection of individuals. Third, under tournaments, the number of positions available is fixed while it varies according to performance in the case of standards. Therefore, if a position needs to be filled, firms are more likely to resort to tournaments.

\subsection{Marginal Productivity Theory}

Marginal productivity theory simply implies that agents are rewarded according to their productivity. In the context of the firm hierarchy, the theory can be associated to models of optimal span of controls, where talent in the higher levels of the hierarchy is diffused through the different layers, implying that talent is more valuable in the higher levels and therefore deserves higher reward (see e.g. Rosen, 1982). An interesting aspect of the academic profession is that it is debatable whether the decisions of individuals in the higher ranks affect the productivity of the workers in the lower ranks. Nevertheless, it can also be argued that talent in the high ranks generates positive externalities on those below them. If individual wages are also set on the basis of past achievements, increasing wage gaps (hypothesis 1) could also reflect the fact that higher ranked individuals have been more productive. Talent reveals itself as individuals start producing. Sorting emerges as a consequence of the survival game, as exit and reallocation proceed. By the same token, if the more able individuals are sorted in the higher wage universities and if individuals have reached the higher ranks following a selection process, then the fact that higher wage gaps lead to higher 
productivity (hypothesis 3) could also be a consequence of the sorting effect, rather than reflecting the incentive effect. There are no clear implication concerning propositions 2 and 4, except if one allows for (positive or negative) externalities of talent, independently of incentives.

\subsection{Our Approach}

Our empirical strategy proceeds as follows. We test the four hypotheses and compare the results with what standards and tournament theory would predict. As shown above, these theories have conflicting implications regarding the effect of the number of individual by rank on the prize and the consequences of the size of the prize on cooperation or sabotage. When performing these tests, we control for marginal productivity theory by disaggregating the wage gap in two components: one part that reflects past productivity differentials and therefore controls for the fact that promotions lead to sorting, and a residual that reflects incentives. The procedure is described in details in section 4 . The next section describes the dataset and discusses the weaknesses of our approach.

\section{Data}

\subsection{University Level Data}

Every year the American Economic Association (AEA) sends to economic departments the Universal Academic Questionnaire (UAQ) where information is asked on, among other things, average salaries by category of jobs (assistant, associate and full professors), the size of the department by category and the number of degrees awarded. We use the answers to these surveys for the years 1977 to 1997, providing a total of 2,100 observations ${ }^{2}$ or on average

\footnotetext{
${ }^{2}$ Unfortunately, only few departments have participated every year so we have an unbalanced panel. From 2,338 university-year pairs, we further excluded observations where we did not have information on all ranks (186 cases), where the average salary was less then $10,000 \$$ (8 outliers), and where the natural rank order was not observed (44 -mostly when assistant professors average wage was higher than associate professors wage). Re-
} 
100 departments a year. Salaries are deflated using the GDP-implicit price deflator (the base year is 1998).

Average real wages have increased over time for all 3 categories. In 1977, an economic department paid on average 64,000 $\$$ to its professors, in 1997 it was about $85,000 \$$. The average wage of associate professors increased from $48,000 \$$ to $63,000 \$$ and the assistant professors from $38,000 \$$ to $53,000 \$$.

Figure 1 shows the evolution of the average wage gap. While the wage difference between associate and full professors has remained quite constant over time, the gap between assistant professors and the other categories has decreased over time. At first sight, our data confirm the first prediction of tournament theory: in 1998, on average, the gap between the salary of an assistant professor and the salary of an associate professor was about $19 \%$ while the gap between the salary of an associate professor and the salary of a full professor was about $35 \%$. This tends to indicate that the wage gap is increasing with the job level.

Another interesting feature of our dataset is that the variance increases with rank as well (Table 1). This could suggest that promotions lead to pay differentiation, while pay is relatively similar at the assistant professor level.

Table 1: Average wage and standard deviation by rank

\begin{tabular}{|c|c|c|}
\hline & Mean & Std. dev. \\
\hline$W_{\text {asst }}$ & 52,588 & 5,879 \\
\hline$W_{\text {assoc }}$ & 62,837 & 10,323 \\
\hline$W_{\text {prof }}$ & 84,750 & 18,272 \\
\hline
\end{tabular}

sults were not affected by the cleaning. One should be aware of two additional features: first, the number of participants in the UAQ has been declining over time, we have 116 observations in 1977 against 79 in 1997. Second, the composition of our sample changes from one year to another, for example, Washington University is present each year, Princeton is present 12 years and Harvard only once. 
Figure 1: The evolution of the wage gap between categories of job

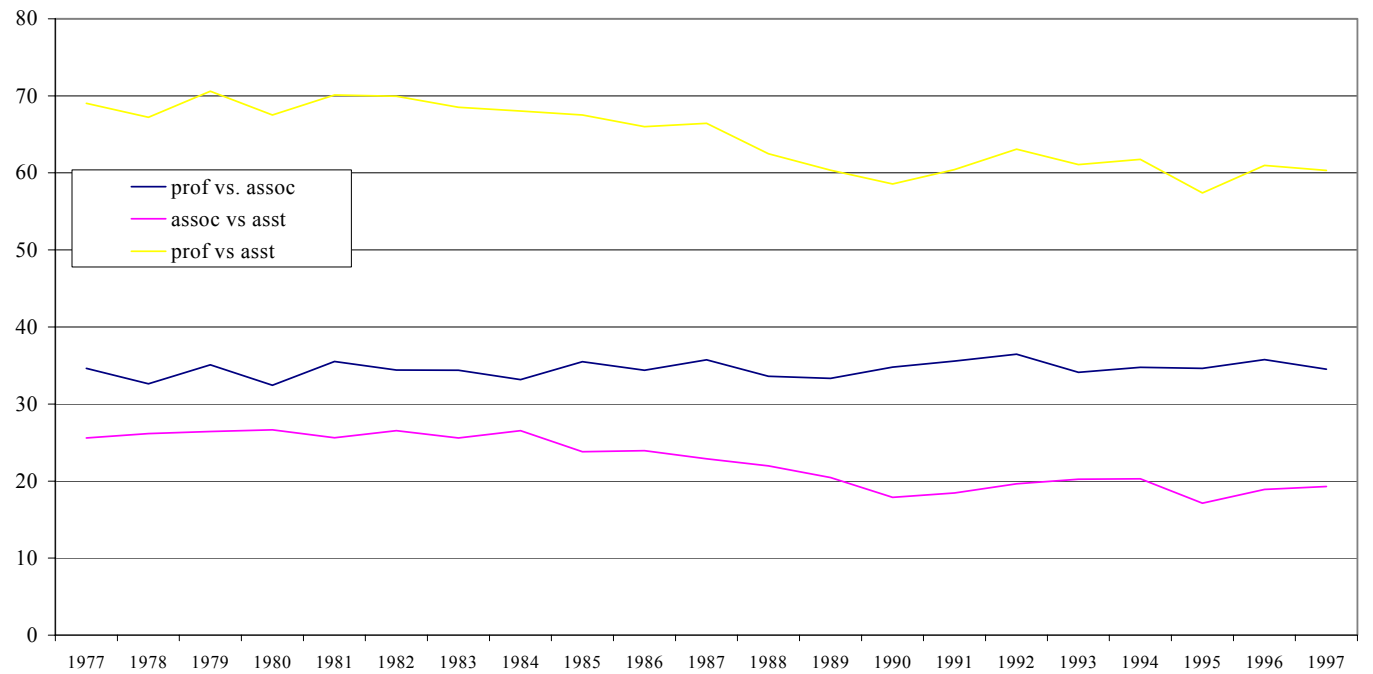

Figure 2: The evolution of the wage gap between private and public universities

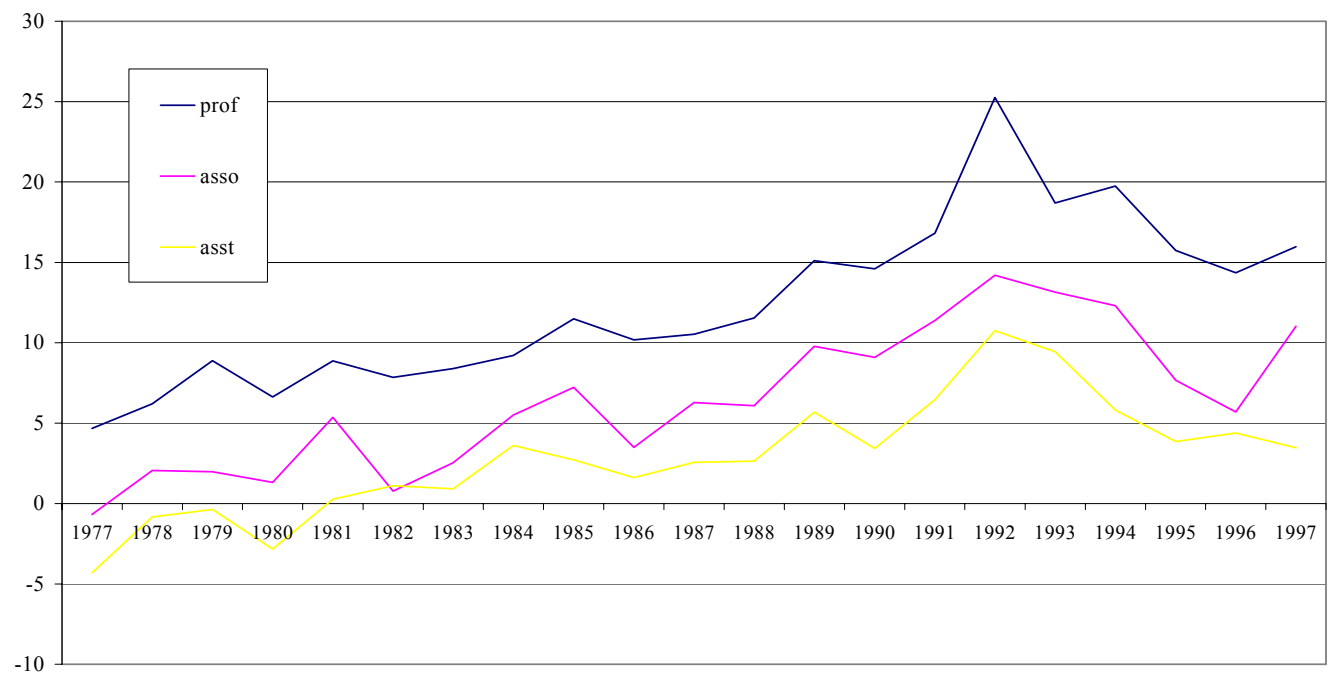


As we also have data on departments in both public (70 to $80 \%$ ) and private (20 to $30 \%$ ) universities, we can bring further evidence on the well known widening gap between public and private universities (see e.g. Alexander, 2001 and The Economist, 2000). Figure 2 shows the evolution of the gap between private and public departments for the different level. Private universities do pay better, especially at the level of the professors. However, the difference for assistant professors is fairly small. Note also that for all three job levels, the difference has increased over time ${ }^{3}$.

\subsection{Internal Labor Markets and the Effect of External Com- petition}

Tournaments take place in the context of an internal labor market with no explicit role for outside options. We check whether this important hypothesis is valid in economic departments. The UAQ also provides information on the number of hires, promotions and leaves by year and by rank. Using all observations for which we have data on the number of faculty in $t$ and $t-1$, and on the internal and external moves, we compute three variables: the percentage of individuals leaving the department by year and by rank, the percentage of newly hired individuals by year and by rank, and the percentage of newly hired individuals coming from outside the department by year and by rank. Table 2 shows the average of these three variables.

Table 2: Average Internal and Outside Mobility

\begin{tabular}{|c|c|c|c|}
\hline Rank & $\begin{array}{c}\text { \% of individuals } \\
\text { leaving the department }\end{array}$ & $\begin{array}{c}\text { \% of new } \\
\text { individuals hired }\end{array}$ & $\begin{array}{c}\% \text { of new individuals } \\
\text { hired from the outside }\end{array}$ \\
\hline \hline Professors & $3.6 \%$ & $5.5 \%$ & $28 \%$ \\
\hline Associates & $3 \%$ & $12.1 \%$ & $25 \%$ \\
\hline Assistants & $1.5 \%$ & $19.1 \%$ & $95.8 \%$ \\
\hline
\end{tabular}

\footnotetext{
${ }^{3} \mathrm{~A}$ problem so far has been that our sample is changing over time. To see whether things would change if we had complete panel, we also looked at the 52 universities for which we have observations both at the beginning and at the end of our period. We basically get the same results.
} 
The average percentage of individuals leaving the department is relatively small and increasing with ranks, while the average percentage of individuals who are new in the department is decreasing with rank, and relatively large at the assistant professor level, which, in the case of the academic labor market, can clearly be described as a port of entry, as $95 \%$ of the new assistant professors are hired from the outside, while this percentage decreases dramatically with rank. These statistics are consistent with the idea of internal competition for jobs. However, around one quarter of new individuals are still hired from the outside at the higher ranks, suggesting that external competition also plays a non negligible role (see Chang, 1996 for a theoretical analysis). Unfortunately, we are not able to control for external competition with our dataset.

\subsection{Individual Data}

We further use information about the entire population of individuals related to 107 universities which were ranked by the NRC in $1993^{4}$. This dataset contains 2,673 individuals and provides the name, rank and university to which they are affiliated during the academic year 1992-1993. These names were linked to the bibliographic information in EconLit. This allows us not only to look at the performance of individuals in terms of research but also gives us the possibility to look at their cooperative behavior (through co-authorship).

The department composition, together with the bibliographic record of each individual, was then matched with the wage dataset. Wages for each layer were available for 50 universities (the list is available from the authors), among them 13 are private. This provides information about 1,291

\footnotetext{
${ }^{4}$ As a robustness check, we also used the 7 th and the 9th edition of the Guide to Graduate Study in Economics to get information on the faculty of the departments. The 7th edition (academic years 1982-1984) gives for each department, the names of the faculty and their rank (from assistant to full professor). The 9th edition (academic year 1994-1995) in addition gives information on the date and the university of Ph.D. though sometimes lacks information on ranks. In a longer version of the paper, we also show the results using this alternative source.
} 
individuals. More than half of them are full professors (694 individuals or $53.8 \%$ of the sample), the category of associate professors is composed of 292 individuals (or $22.6 \%$ of the sample) and the others are assistant professors (305 individuals, or $23.6 \%$ of the sample).

To disaggregate university production by category of job, we use the list of the names and the ranks of individuals working in the department as provided in the 1992 survey of the NRC. For each individual, we constructed the publication history between 1969 and 1998 from EconLit. This allows us to compute the mean number of publications per rank for each of the 107 doctoral programs included in the NRC survey.

Publications are adjusted for quality and corrected for coauthorship, dividing the weight of the paper by the number of coauthors. Different quality weights have been proposed in the literature an we selected one methodology, suggested in Bauwens (1998). Each journal receives a weight between one and five on the basis of the product of the impact factor and the total number of citations received during a given year (the latter reflecting better the long run) and then gives weight 1 to journals not included in the Journal Citation Report (JCR) but included in Econlit, because the non-JCR included journals are quite likely to be rarely cited ones. This method has the advantage of being simple and of weighting all journals. One disadvantage is that weights can be seen as relatively subjective. We also used publications weighted by the impact factor or the Laband and Piette corrected impact factor of the journal and this yielded comparable results.

It is important to stress that, while we gain some insight on the potential variables influencing wages, we lose the time dimension. We were unfortunately not able to follow the career of individuals ${ }^{5}$ as the survey was not continued in subsequent years.

\footnotetext{
${ }^{5}$ In Coupé et al. (2003), we follow the career of a sample of 1,000 top economists and linked their productivity to their career achievements, but without information about individual wages.
} 


\section{Empirical analysis}

\subsection{Increasing Wage Gaps}

Our first test is to determine whether tournament prize (the wage gap) is increasing along the promotion ladder. We regress the log of average wage over a dummy for associate, a dummy for full professor and some controls.

$$
\log W_{j r t}=\alpha_{0}+\alpha_{1} A S S O+\alpha_{2} P R O F+\alpha_{3} Z_{j t}+\varepsilon_{j r t}
$$

where $j$ is an index for the university, $r$ is an index for rank $(r=P R O F$, $A S S O, A S S T)$ and $t$ is a time index. The variables included as controls are a dummy for private universities and the size of the university (measured by the number of degrees awarded, in hundreds), the latest being less well reported. Results are presented in table 3 .

Table 3: Wages and Ranks

\begin{tabular}{|c|c|c|}
\hline Dep.var.: $\log W$ & coeff (s.e.) & \\
\hline$A S S O$ & $0.20^{* * *}(0.005)$ & $0.20^{* * *}(0.004)$ \\
\hline$P R O F$ & $0.49^{* * *}(0.005)$ & $0.49^{* * *}(0.004)$ \\
\hline Nr.BA & - & $0.07^{* * *}(0.004)$ \\
\hline$P R I V$ & - & $0.05^{* * *}(0.002)$ \\
\hline constant & $10.63^{* * *}(0.004)$ & $10.57^{* * *}(0.004)$ \\
\hline Year dummies & NO & YES \\
\hline Nr.Obs. & 6300 & 5721 \\
\hline Adj. $\mathrm{R}^{2}$ & 0.56 & 0.75 \\
\hline
\end{tabular}

Note: standard errors in parentheses, ${ }^{* * *}$ denotes statistical significance at the $1 \%$ level

We find evidence of an increasing relationship between wage and the job level. As one moves up in the hierarchy, the gap increases. As can be seen in the first column, job levels alone explain $56 \%$ of the variance. This finding supports one implication from tournament theory that the gap between each layer of the hierarchy should become larger and larger, so as to provide incentives to tournament participants to exert effort and win the prize. Size of the institution and its ownership also play an important role in wage determination. 
However, one could argue that wage differentials simply reflect productivity differentials. To control for this possibility, we need a measure of performance for each hierarchical layer. Universities are likely to reward individuals on the basis of past accomplishments, reflecting their reputation which increases the prestige of the university to which they are associated. We create a variable called average past publication by rank (PPUB) by summing all papers produced by the individuals in our sample over the period 1969-1992 over ranks and dividing by the number of individuals by rank. We regress the $\log$ of wage gaps over the $\log$ of $P P U B$ for all ranks, controlling for ranks, as in Eq. (2):

$$
\log W_{j r}=\delta_{0}+\delta_{1} A S S O+\delta_{2} P R O F+\delta_{3} \log P P U B_{j r}+\varepsilon_{j r}
$$

\section{Table 4: Wages and Past Performance}

\begin{tabular}{|c|c|}
\hline Dep.var.: & $\log W$ \\
\hline constant & $10.57^{* * *}(0.03)$ \\
\hline $\log P P U B$ & $0.08^{* * *}(0.02)$ \\
\hline$A S S O$ & $0.08^{* *}(0.03)$ \\
\hline$P R O F$ & $0.38^{* * *}(0.04)$ \\
\hline Nr.Obs & 150 \\
\hline Adj. $\mathrm{R}^{2}$ & 0.79 \\
\hline
\end{tabular}

Note: see table 3

In table 4 , we find that publications matter, but also that promotion premia are lower when controlling for production differentials. The raw gaps for this subsample of 50 universities are 19\% (from assistant to associate) and $54 \%$ (from associate to professor). Correcting for past performance, we get gaps of $8 \%$ and $38 \%$. Despite this reduction is size, we still find increasing wage gaps.

We also ran the equation for each rank separately:

$$
\log W_{j r}=\gamma_{0}+\gamma_{1} \log P P U B_{j r}+\varepsilon_{j r}^{\prime} \forall r
$$


Table 5: wage and past performance (by type of job)

\begin{tabular}{|c|c|c|c|}
\hline Dep.var.: & $\log W_{\text {prof }}$ & $\log W_{A S S O}$ & $\log W_{A S S T}$ \\
\hline constant & $10.37^{* * *}(0.14)$ & $10.61^{* * *}(0.1)$ & $10.79^{* * *}(0.02)$ \\
\hline $\log P P U B$ & $0.27^{* * *}(0.04)$ & $0.13^{* * *}(0.03)$ & $0.02(0.015)$ \\
\hline Nr.Obs & 50 & 50 & 50 \\
\hline Adj. $\mathrm{R}^{2}$ & 0.50 & 0.22 & 0.01 \\
\hline
\end{tabular}

Note: see table 3

Table 5 presents the results. An interesting finding is that wages are more performance related at higher levels of the hierarchy. This appears to indicate a learning and selection effect, the most productive scholars being allocated to the more lucrative positions. This relates to the stylized fact that the variance of wages was more important for higher ranks.

One way to control for university fixed effects in the salary level would be to regress the difference of the log wages over the difference of the log past publications. Indeed, if

$$
\begin{aligned}
\log W_{j, P R O F} & =\alpha_{0}+\alpha_{1} \log P P U B_{j, P R O F}+\nu_{j}+\xi_{P R O F} \\
\log W_{j, A S S O} & =\alpha_{0}^{\prime}+\alpha_{1}^{\prime} \log P P U B_{j, A S S O}+\nu_{j}+\xi_{A S S O} \\
\log W_{j, A S S T} & =\alpha_{0}^{\prime \prime}+\alpha_{1}^{\prime \prime} \log P P U B_{j, A S S T}+\nu_{j}+\xi_{A S S T}
\end{aligned}
$$

where $\varepsilon_{j r}=\nu_{j}+\xi_{j r}, \nu_{j}$ is university fixed effect and $\xi_{j r} \sim N\left(0, \sigma_{j r}\right)$.

Then, by regressing instead

$\log W_{j, P R O F}-\log W_{j, A S S O}=\beta_{0}+\beta_{1}\left(\log P P U B_{j, P R O F}-\log P P U B_{j, A S S O}\right)+\varepsilon_{P-A}$

and similarly we get rid of the university fixed effect.

$\log W_{j, A S S O}-\log W_{j, A S S T}=\beta_{0}^{\prime}+\beta_{1}^{\prime}\left(\log P P U B_{j, A S S O}-\log P P U B_{j, A S S T}\right)+\varepsilon_{A-A}$

Results are presented in table 6 . We find a positive effect of publication: higher wage gaps are partly explained by higher publication gaps. Moreover, the difference in the constant again indicates an increasing wage gap. Finally, the sensitivity of wage gaps to productivity differences increases along 
the career. What we do not control for in this specification is that there could be a university-by-rank fixed effects. To properly address this issue, we would have needed a panel dataset.

A related alternative explanation for wage gaps is experience. Individuals would accumulate human capital and wages would be linked to seniority. Changes in experience could also have an influence on the evolution of the wage gap. We checked this hypothesis using individual data of the 9th Guide to Graduate Study in Economics which gave for some universities the year of Ph.D. Controlling for the average experience level, we did not find significant effect of experience. It is likely that this finding is due to the lack of sufficient variation in average experience level by rank.

Table 6: Wage Gaps and Past Publication Differences

\begin{tabular}{|c|c|c|}
\hline Dep.var.: & $\log W_{P R O F}-\log W_{A S S O}$ & $\log W_{A S S O}-\log W_{A S S T}$ \\
\hline constant & $0.28^{* * *}(0.026)$ & $0.15^{* * *}(0.022)$ \\
\hline $\log P P U B_{P R O F}-\log P P U B_{A S S O}$ & $0.12^{* * *}(0.034)$ & - \\
\hline $\log P P U B_{A S S O}-\log P P U B_{A S S T}$ & - & $0.027^{* *}(0.01)$ \\
\hline Nr.Obs & 50 & 50 \\
\hline Adj. R ${ }^{2}$ & 0.18 & 0.06 \\
\hline
\end{tabular}

Note: see table 3

There are also some elements that could explain the variation across departments for which we can not control such as differences in teaching loads. However, given the relative (compared to publications) unobservability of the quality of teaching, relatively to other contestants, universities are less likely to provide incentives in this area. A more pragmatic reason for ignoring it was that the data were not available.

To sum up, economic departments have increasing wage gaps and this finding can not be entirely explained by performance differentials. This suggests that incentive-related motivations might lie at the origin of this finding. We also find evidence of sorting, as wages become more performance related at higher ranks. 


\subsection{The Prize and the Number of Contestants}

The second hypothesis that we want to test is whether the wage gap between job ladders is a function of the number of participants. The more there are participants, the more complicated it should be to win the prize, and therefore, ex ante, a bigger reward should be needed to provide sufficient incentives to contestants. We therefore regress the wage gap between the full professor level and the associate professor level over the number of associate professors waiting for promotion, controlling for size and type of institution.

$$
\log G A P_{j, P R O F-A S S O}=f\left(N R . A S S O_{j}, P R I V_{j}, S I Z E_{j}\right)
$$

and similarly, we regress the wage gap between the associate professor level and the assistant professor level on the number of assistant professors and the same controls as in the previous regression.

$$
\log G A P_{j, A S S O-A S S T}=f\left(N R . A S S T_{j}, P R I V_{j}, S I Z E_{j}\right)
$$

Results are provided in table 7 . The number of contenders is positively and significantly related to the wage spread, in line with tournament theory. The more people are fighting for the prize, the larger should the prize be. The relationship is apparently stronger for the gap at the lower level $\left(G A P_{A S S O-A S S T}\right)$.

Table 7: Effect of the number of contestants on the wage gap

\begin{tabular}{|c|c|c|}
\hline Dep.var.: & $\log G A P_{P R O F-A S S O}$ & $\log G A P_{A S S O-A S S T}$ \\
\hline Nr. Contestants & $0.017^{* * *}(0.004)$ & $0.019^{* * *}(0.005)$ \\
\hline Nr.BA & $0.18^{* * *}(0.01)$ & $0.12^{* * *}(0.015)$ \\
\hline PRIV & $0.33^{* * *}(0.028)$ & $0.23^{* * *}(0.03)$ \\
\hline constant & $9.30^{* * *}(0.005)$ & $8.85^{* * *}(0.06)$ \\
\hline Nr.Obs. & 1853 & 1852 \\
\hline Adj. $\mathrm{R}^{2}$ & 0.19 & 0.10 \\
\hline
\end{tabular}

Note: see table 3

There are two problems associated with our specification. The first difficulty is that part of the wage gap reflects differences in average past productivity between ranks. To control for differences in productivity by rank, 
we first regress the log of the wage gap over the log of the gap in average cumulative publications (see Eq. 4 and 5).

The part which is not explained by the publication differential is the corrected wage gap $(C G A P)$. We then regress the corrected wage gap over the number of (absolute and relative) contestants.

$$
\begin{aligned}
& C G A P_{j, P R O F-A S S O}=f\left(N R . C O N T E S T A N T S_{j}\right) \\
& C G A P_{j, A S S O-A S S T}=f\left(N R . C O N T E S T A N T S_{j}\right)
\end{aligned}
$$

Results are reported in tables 8 . We find a positive and slightly significant effect of the number of assistant professors per associate professor, but a negative and significant effect of the number of associate professors per professor. The result can be linked to the observed hierarchical structure of economic departments. Contrarily to firms where the hierarchy is organized in a pyramide-like scheme, the largest layer in departments is composed of professors, while the number of associates is usually smaller than the number of assistants. This could explain why there seems to be a tournament effect in the first round of promotion (from assistant to associate), but not in the second. To sum up, we do not find a clear effect of the number of contestants on the wage gap.

Table 8: The effect of the number of (absolute) contestants on the corrected wage gap

\begin{tabular}{|c|c|c|}
\hline Dep.var.: & $C G A P_{P R O F-A S S O}$ & $C G A P_{A S S O-A S S T}$ \\
\hline Nr. Contestants & $0.006(0.005)$ & $0.007^{*}(0.004)$ \\
\hline constant & $0.32^{* * *}(0.035)$ & $0.11^{* * *}(0.02)$ \\
\hline Nr.Obs. & 50 & 50 \\
\hline Adj. $\mathrm{R}^{2}$ & 0.01 & 0.04 \\
\hline
\end{tabular}

Note: see table 3

The second problem is that we use the absolute number of contestants. By doing this, we do not control for the number of positions available. In the literature on firms one generally takes the number of board-members (in other words, divided by $1 \mathrm{CEO}$ ) as a proxy for the chance of winning 
the prize ${ }^{6}$. A solution could be to divide the number of contestants by the number of existing positions in the upper level. Indeed one could argue that the probability to be promoted will increase with the number of existing positions. However, the fact that there are many people in the higher ranks can also mean that the positions have been filled recently. Our results were not qualitatively different using this definition.

\subsection{Incentive Effect}

Do economists at the assistant and associate level produce more in higher gaps universities? Are people responding to incentives? To check this, we test whether we can find a relationship between production on the one hand and wage gap on the other. To avoid reversed causality, we use individual publications (weighted for coauthorship and adjusted for quality, as for past publications) during the period 1993-1995 as a measure of performance (PERF).

We regress this productivity variable over the log of the wage gap in the university where the individual is affiliated:

$$
P E R F_{i}=\lambda_{0}+\lambda_{1} G A P_{j r}+\lambda_{2} A S S O+\varepsilon_{i}
$$

where $G A P_{j r}$ is $\log G A P_{j, A S S O-A S S T}$ if individual $i$ is assistant professor and $\log G A P_{j, P R O F-A S S O}$ if he is associate. We find a positive and significant effect of the wage gap on individual performance (table 9). A doubling of the wage gap would lead to an increase of the average production by rank of 1 AER-equivalent article. Assistant professors in our sample appear to be more productive than associate professors. This comparison only reflects cross-sectional differences between individuals in the subsamples, and not necessarily a dynamic reduction of productivity after the first promotion (on the latest see Coupé et al., 2003).

\footnotetext{
${ }^{6}$ Eriksson (1999) finds that for each additional manager with "significant" responsibilities, the wage gap increase by $1.8 \%$. Conyon et al. (2001) find that each additional board-member increases the gap by $3.5 \%$. Bognanno (2001) finally shows that each additional vice president increases the gap between the president and the vice-presidents salary by $4 \%$.
} 
Table 9: Effect of the wage gap on performance

\begin{tabular}{|c|c|}
\hline Dep.var.: & PERF \\
\hline$G A P$ & $5.35^{* *}(2.15)$ \\
\hline ASSO & $-2.37^{* * *}(0.55)$ \\
\hline constant & $4.95^{* * *}(0.53)$ \\
\hline Nr.Obs. & 597 \\
\hline Adj. $\mathrm{R}^{2}$ & 0.03 \\
\hline
\end{tabular}

Note: see table 3

Previously we noticed that part of the wage gap was due not to incentives reasons but to productivity differential. To correct for this, we use once again the corrected wage gap instead of the observed wage gap:

$$
P E R F_{i}=\lambda_{0}^{\prime}+\lambda_{1}^{\prime} C G A P_{j r}+\lambda_{2}^{\prime} A S S O_{i}+\varepsilon_{i}^{\prime}
$$

Results are presented in table 10 . We see that when we use the part of the wage gap reflecting pure incentives, we find a more important effect of the wage gap, a doubling of the corrected wage gap being associated with an increase by 1.5 AER equivalent article on average.

Table 10: Effect of the corrected wage gap on performance

\begin{tabular}{|c|c|}
\hline Dep.var.: & PERF \\
\hline$C G A P$ & $7.83^{* * *}(2.31)$ \\
\hline ASSO & $-1.46^{* * *}(0.45)$ \\
\hline constant & $5.95^{* * *}(0.32)$ \\
\hline Nr.Obs. & 597 \\
\hline Adj. $\mathrm{R}^{2}$ & 0.04 \\
\hline
\end{tabular}

Note: see table 3

\subsection{Cooperation}

A disadvantage of tournament incentives is that they will decrease the willingness to cooperate with colleagues of the same rank. We ask two questions: first, do professors collaborate more internally (within department) within 
rank as they are not in competition anymore? Second, do we find more 'internal within rank' cooperation in departments that have smaller wage gaps? The idea behind this test is that high prize associated with promotions will discourage potential contestants to collaborate when performance is relative but not when there is an absolute threshold to beat ${ }^{7}$.

To test these two hypotheses, we create a variable called internal cooperation within rank $(I C W R)$ by dividing the number of papers coauthored within university within rank (i.e. with other contestants) by the total number of publications, over the period 1993-1995. We also create a variable called cooperation $(C O O P)$ by dividing coauthored papers by the total number of papers over the same period. To provide a snapshot of how cooperative behavior depends on rank, average internal cooperation within rank and cooperation are presented in table 11.

\section{Table 11: cooperation and rank}

\begin{tabular}{|c|c|c|}
\hline & $C O O P$ & $I C W R$ \\
\hline Assistant & 0.57 & 0.06 \\
\hline Associate & 0.71 & 0.04 \\
\hline Professor & 0.64 & 0.09 \\
\hline
\end{tabular}

Note: standard deviations in parentheses

We find that, among those economists who published at least one paper over the period (949 individuals or $73.5 \%$ of the sample), $63.5 \%$ of the papers are coauthored. Moreover, associate professors are those who cooperated more during that period. On the other hand, they are also those who cooperated less within rank. However, the number of associate professors is often smaller than the number of assistant professors and much smaller than the number of professors.

We then relate $I C W R$ to the log of the wage gap as in the previous subsection. Because there are a lot of people who do not cooperate at all or cooperate on all their papers, we prefer to use a dichotomic variable as

\footnotetext{
${ }^{7}$ We do not consider the strategic formation of coalitions between potential contestants in a multi-prize tournament setting. To rule this out, it is enough to assume that learning about talent is slow so that potential contestants can not assess their relative quality.
} 
dependent variable and create a dummy $D I C W R$ equal to 1 if individual cooperated internally within rank on at least one paper and 0 otherwise. Individuals who did not publish did not cooperate neither and were assigned value of 0 (we relax this assumption infra). In our sample, 43 assistant professors (around 14\% of the sample) and 23 associate professors (around $8 \%$ of the sample) cooperated within rank.

We run a probit analysis:

$$
\begin{gathered}
I C W R_{i}^{*}=\mu_{0}+\mu_{1} G A P_{j r}+\mu_{2} A S S O_{i}+\varepsilon_{i} \\
D I C W R_{i}=1 \text { if } I C W R_{i}^{*}>0 \\
D I C W R_{i}=0 \text { if } I C W R_{i}^{*} \leq 0
\end{gathered}
$$

Table 12: Effect of the wage gap on cooperation

\begin{tabular}{|c|c|}
\hline Dep.var.: & DICWR \\
\hline$G A P$ & $-0.078(0.129)$ \\
\hline$A S S O$ & $-0.052^{*}(0.03)$ \\
\hline Nr.Obs. & 597 \\
\hline Pseudo R $^{2}$ & 0.02 \\
\hline Log likelihood & -204.4 \\
\hline
\end{tabular}

Note: see table 3

Table 12 shows the marginal changes. We find negative but not significant effect of the wage gap. Cooperative behavior within rank does not appear to be affected by wage gaps. On the other hand, we find that associate professors tend to cooperate significantly less within rank.

Finally, we regress $I C W R$ on the corrected wage gap:

$$
I C W R_{i}=\mu_{0}^{\prime}+\mu_{1}^{\prime} C G A P_{j r}+\mu_{2}^{\prime} A S S O_{i}+\varepsilon_{i}
$$


Table 13: Effect of the corrected wage gap on cooperation

\begin{tabular}{|c|c|}
\hline Dep.var.: & $I C W R$ \\
\hline$C G A P$ & $0.146(0.136)$ \\
\hline$A S S O$ & $-0.059^{* *}(0.025)$ \\
\hline Nr.Obs. & 597 \\
\hline Adj. $\mathrm{R}^{2}$ & 0.02 \\
\hline Log likelihood & -204 \\
\hline
\end{tabular}

Table 13 shows that the same conclusions prevail: the wage gap does not affect significantly cooperation within rank and associate professors appear to cooperate less internally within rank.

We also added the number of colleagues by rank as an additional control but results were unchanged. However, when we considered the subsample of individuals who published, then the associate professor dummy was no longer significant and the number of colleagues had a positive effect on internal cooperation within rank.

\section{Discussion and Conclusion}

We have used a very rich panel dataset providing average wage and department size at each level of the economic departments' hierarchy over more than twenty years to test empirically key elements of tournament theory. We provide evidence that wage gaps are increasing with the job level, even when controlling for differences in productivity by rank. Moreover, average wages increase with productivity along the career, suggesting the presence of sorting, as the more productive economists are being matched with the more productive universities, which also pay higher wages. We find that individual productivity is positively linked to wage gaps, i.e. wage gaps have an incentive effect. However, we do not find strong evidence that the number of contestants influences wage gaps, nor that wage gaps are associated with less cooperation among contestants. These findings would tend to support the existence of standards rather than tournaments in economic 
departments.

An additional way, suggested by Gibbs (1994), to distinguish between these two theories is to examine the extent to which job slots are fixed. To check this, we looked whether the organizational structure remained stable over time by comparing the share of each hierarchical layer in 1983 and 1992. On average, these shares changed by about $10 \%$ over a ten year period, which again goes in favor of standards.

Why would economic departments choose standards rather than tournaments? Part of the answer could be linked to the importance of selecting high quality candidates. Standards allow a better control over quality than tournaments by setting an absolute threshold. Given that promotions are associated with high job security, the decision is often irreversible and costs of a wrong selection could be very high. Another reason could be the importance of cooperation or more generally helping your colleagues for their research.

However, the costs and benefits of using one rather than another promotion system could vary over time. For example, the standard used could depend on the supply of talented individuals and therefore will contain a part of comparison. A similar result is obtained if the organization is constrained by quantity or budget and only offers a limited amount of slots. Another aspect to be considered is the dynamic nature of the way standards are set. While considered as exogenous by the contestants, standards are established by the organization so as to guarantee a given level of sorting and are probably set by learning by doing, i.e. by observing the effect of previously established standards on the (past) talent pool and can be interpreted as a tournament against the past. These remarks imply that the distinction between standards and tournaments is less clear cut in reality. These issues are left for future research. 


\section{References}

[1] Alexander, F.K. (2000), The Silent Crisis: The Fiscal Capacity of Public Universities to Compete for Faculty, Review of Higher Education, Forthcoming.

[2] Bauwens, L. (1998), A New Method to Rank University Research and Researchers in Economics in Belgium, Working Paper, CORE.

[3] Becker, Brian E. and Huselid, Mark A. (1992), The Incentive Effects of Tournament Compensation Systems, Administrative Science Quarterly, $37,336-350$.

[4] Bognanno, Michael L. (2001), Corporate Tournaments, Journal of Labor Economics, 19, 290-315.

[5] Chan, William (1996), External Recruitment versus Internal Promotion, Journal of Labor Economics, 14, 555-570.

[6] Conyon, Martin J., Peck, Simon I. and Sadler, Graham (1999), Corporate tournaments and executive compensation, mimeo, University of Warwick.

[7] Coupé, Tom, Smeets, Valérie and Warzynski, Frédéric (2003), Incentives, Sorting and Productivity Along the Career, working paper, Aarhus School of Business.

[8] Ehrenberg, Ronald G. and Bognanno, Michael L. (1990a), The Incentive Effects of Tournaments Revisited: Evidence from the European PGA Tour, Industrial and Labor Relations Review, 43, 74S-88S.

[9] Ehrenberg, Ronald G. and Bognanno, Michael L. (1990b), Do Tournaments Have Incentive Effects?, Journal of Political Economy, 98, 13071324 .

[10] Eriksson, Tor (1999), Executive Compensation and Tournament Theory: Empirical tests on Danish Data, Journal of Labor Economics, 17, 262-280. 
[11] Gibbs, Michael (1994), Testing Tournaments? An Appraisal of the Theory and Evidence, Labor Law Journal, 45, 493-500.

[12] Gibbs, Michael (1996), Promotion and Incentives, working paper, Graduate School of Business, University of Chicago.

[13] Lazear, Edward and Rosen, Sherwin (1981), Rank Order Tournaments as Optimal Labor Contracts, Journal of Political Economy, 89, 841-864.

[14] Lazear, Edward (1989), Pay Equality and Industrial Politics, Journal of Political Economy, 97, 561-580.

[15] McLaughlin, Kenneth J. (1988), Aspects of Tournament Models: A Survey, Research in Labor Economics, 9, 225-256.

[16] Nalebuff, Barry J. and Stiglitz, Joseph E. (1983), Prizes and incentives: towards a general theory of compensation and competition, Bell Journal of Economics, 14, 21-43.

[17] Prendergast, Canice (1999), The Provision of Incentives in Firms, Journal of Economic Literature, 37, 7-63.

[18] Rosen, Sherwin (1982), Authority, control and the distribution of earnings, Bell Journal of Economics, 13, 311-323.

[19] Rosen, Sherwin (1986), Prizes and Incentives in Elimination Tournaments, American Economic Review, 76, 701-715.

[20] The Economist (2000), University Education: The Gap Widens, $22 / 04 / 2000$. 
Department of Economics:

Skriftserie/Working Paper:

2002:

WP 02-1 Peter Jensen, Michael Rosholm and Mette Verner: A Comparison of Different Estimators for Panel Data Sample Selection Models. ISSN 1397-4831.

WP 02-2 Erik Strøjer Madsen, Camilla Jensen and Jørgen Drud Hansen: Scale in Technology and Learning-by-doing in the Windmill Industry. ISSN 1397-4831.

WP 02-3 Peter Markussen, Gert Tinggaard Svendsen and Morten Vesterdal: The political economy of a tradable GHG permit market in the European Union. ISSN 13974831 .

WP 02-4 Anders Frederiksen og Jan V. Hansen: Skattereformer: Dynamiske effekter og fordelingskonsekvenser. ISSN 1397-4831.

WP 02-5 Anders Poulsen: On the Evolutionary Stability of Bargaining Inefficiency. ISSN $1397-4831$.

WP 02-6 Jan Bentzen and Valdemar Smith: What does California have in common with Finland, Norway and Sweden? ISSN 1397-4831.

WP 02-7 Odile Poulsen: Optimal Patent Policies: A Survey. ISSN 1397-4831.

WP 02-8 Jan Bentzen and Valdemar Smith: An empirical analysis of the interrelations among the export of red wine from France, Italy and Spain. ISSN 1397-4831.

WP 02-9 A. Goenka and O. Poulsen: Indeterminacy and Labor Augmenting Externalities. ISSN 1397-4831.

WP 02-10 Charlotte Christiansen and Helena Skyt Nielsen: The Educational Asset Market: A Finance Perspective on Human Capital Investment. ISSN 1397-4831.

WP 02-11 Gert Tinggaard Svendsen and Morten Vesterdal: CO2 trade and market power in the EU electricity sector. ISSN 1397-4831.

WP 02-12 Tibor Neugebauer, Anders Poulsen and Arthur Schram: Fairness and Reciprocity in the Hawk-Dove game. ISSN 1397-4831.

WP 02-13 Yoshifumi Ueda and Gert Tinggaard Svendsen: How to Solve the Tragedy of the Commons? Social Entrepreneurs and Global Public Goods. ISSN 1397-4831.

WP 02-14 Jan Bentzen and Valdemar Smith: An empirical analysis of the effect of labour market characteristics on marital dissolution rates. ISSN 1397-4831. 
WP 02-15 Christian Bjørnskov and Gert Tinggaard Svendsen: Why Does the Northern Light Shine So Brightly? Decentralisation, social capital and the economy. ISSN 13974831 .

WP 02-16 Gert Tinggaard Svendsen: Lobbyism and $\mathrm{CO}_{2}$ trade in the EU. ISSN 1397-4831.

WP 02-17 Søren Harck: Reallønsaspirationer, fejlkorrektion og reallønskurver. ISSN 13974831.

WP 02-18 Anders Poulsen and Odile Poulsen: Materialism, Reciprocity and Altruism in the Prisoner's Dilemma - An Evolutionary Analysis. ISSN 1397-4831.

WP 02-19 Helena Skyt Nielsen, Marianne Simonsen and Mette Verner: Does the Gap in Family-friendly Policies Drive the Family Gap? ISSN 1397-4831.

2003:

WP 03-1 Søren Harck: Er der nu en strukturelt bestemt langsigts-ledighed I SMEC?: Phillipskurven i SMEC 99 vis-à-vis SMEC 94. ISSN 1397-4831.

WP 03-2 Beatrice Schindler Rangvid: Evaluating Private School Quality in Denmark. ISSN 1397-4831.

WP 03-3 Tor Eriksson: Managerial Pay and Executive Turnover in the Czech and Slovak Republics. ISSN 1397-4831.

WP 03-4 Michael Svarer and Mette Verner: Do Children Stabilize Marriages? ISSN 13974831 .

WP 03-5 Christian Bjørnskov and Gert Tinggaard Svendsen: Measuring social capital - Is there a single underlying explanation? ISSN 1397-4831.

WP 03-6 Vibeke Jakobsen and Nina Smith: The educational attainment of the children of the Danish 'guest worker' immigrants. ISSN 1397-4831.

WP 03-7 Anders Poulsen: The Survival and Welfare Implications of Altruism When Preferences are Endogenous. ISSN 1397-4831.

WP 03-8 Helena Skyt Nielsen and Mette Verner: Why are Well-educated Women not Fulltimers? ISSN 1397-4831.

WP 03-9 Anders Poulsen: On Efficiency, Tie-Breaking Rules and Role Assignment Procedures in Evolutionary Bargaining. ISSN 1397-4831.

WP 03-10 Anders Poulsen and Gert Tinggaard Svendsen: Rise and Decline of Social Capital - Excess Co-operation in the One-Shot Prisoner's Dilemma Game. ISSN 13974831 . 
WP 03-11 Nabanita Datta Gupta and Amaresh Dubey: Poverty and Fertility: An Instrumental Variables Analysis on Indian Micro Data. ISSN 1397-4831.

WP 03-12 Tor Eriksson: The Managerial Power Impact on Compensation - Some Further Evidence. ISSN 1397-4831.

WP 03-13 Christian Bjørnskov: Corruption and Social Capital. ISSN 1397-4831.

WP 03-14 Debashish Bhattacherjee: The Effects of Group Incentives in an Indian Firm - Evidence from Payroll Data. ISSN 1397-4831.

WP 03-15 Tor Eriksson och Peter Jensen: Tidsbegränsade anställninger - danska erfarenheter. ISSN 1397-4831.

WP 03-16 Tom Coupé, Valérie Smeets and Frédéric Warzynski: Incentives, Sorting and Productivity along the Career: Evidence from a Sample of Top Economists. ISSN 1397-4831.

WP 03-17 Jozef Koning, Patrick Van Cayseele and Frédéric Warzynski: The Effects of Privatization and Competitive Pressure on Firms' Price-Cost Margins: Micro Evidence from Emerging Economies. ISSN 1397-4831.

WP 03-18 Urs Steiner Brandt and Gert Tinggaard Svendsen: The coalition of industrialists and environmentalists in the climate change issue. ISSN 1397-4831.

WP 03-19 Jan Bentzen: An empirical analysis of gasoline price convergence for 20 OECD countries. ISSN 1397-4831.

WP 03-20 Jan Bentzen and Valdemar Smith: Regional income convergence in the Scandinavian countries. ISSN 1397-4831.

WP 03-21 Gert Tinggaard Svendsen: Social Capital, Corruption and Economic Growth: Eastern and Western Europe. ISSN 1397-4831.

WP 03-22 Jan Bentzen and Valdemar Smith: A Comparative Study of Wine Auction Prices: Mouton Rothschild Premier Cru Classé. ISSN 1397-4831.

WP 03-23 Peter Guldager: Folkepensionisternes incitamenter til at arbejde. ISSN 1397-4831.

WP 03-24 Valérie Smeets and Frédéric Warzynski: Job Creation, Job Destruction and Voting Behavior in Poland. ISSN 1397-4831.

WP 03-25 Tom Coupé, Valérie Smeets and Frédéric Warzynski: Incentives in Economic Departments: Testing Tournaments? ISSN 1397-4831. 